\title{
Os mundos morais possíveis de Mackie e MacIntyre
}

\author{
The possible moral worlds \\ of Mackie and MacIntyre
}

\section{Hippolyto R. da S. Ribeiro}

Mestre em Filosofia pela UFPEL

Resumo: Analisamos nesse artigo as principais características filosóficas do ceticismo moral de Mackie e do contextualismo moral de MacIntyre. Do ponto-de-vista ontológico. Reivindicamos que Mackie e MacIntyre adotam ontologias diferentes. Mackie adota uma ontologia fisicalista ou materialista e MacIntyre uma ontologia social e cultural. Por essa razão, Mackie conclui que valores morais não são objetivos, enquanto MacIntyre conclui, ao contrário, que valores morais são objetivos. Do ponto-de-vista linguístico. Reivindicamos que a teoria do 'erro' de Mackie postula que o uso da linguagem moral ocidental é baseado numa crença (falsa) na objetividade dos valores morais, e a teoria do desacordo moral contemporâneo de MacIntyre propõe, ao contrário, que o uso da linguagem moral na sociedade pós-moderna é baseado numa crença (falsa) na subjetividade dos valores morais.

Palavras-chave: Ética; Ceticismo; Contextualismo; Ontologia Moral; Linguística; Objetividade.

Abstract: We analyze in this article the mais philosophical characteristics of the moral skepticism of Mackie and the moral contextualism of MacIntyre. From the ontological point of view, we claim that Ma- 
ckie and MacIntyre adopt different ontologies. Mackie takes a physicalist ontology or materialistic and MacIntyre a social and cultural ontology. For this reason, Mackie concludes that moral values are not objective, whereas MacIntyre concludes, on the contrary, that moral values are objetive. From the linguistic point of view, Mackie's theory of 'error' postulates that the use of Western moral language is based on a (false) belief in the objectivity of moral values, whereas MacIntyre's theory of contemporary moral disagreement proposes, unlike, that the use of moral language in postmodern society is based os a (false) belief in the subjectivity of moral values.

Keywords: Ethics; Skepticism; Contextualism; Moral Ontology; Linguistics; Objectivity.

\section{Introdução}

naliso nesse artigo as principais características filosóficas 1 de dois mundos (morais) possíveis propostos por Mackie e MacIntyre. Reivindicando que Mackie e MacIntyre sugerem que habitamos em mundos ontológicos, linguísticos e éticos completamente diferentes e contraditórios. Do ponto-de-vista ontológico. Mackie acredita que vivemos em um mundo sem valores morais objetivos. MacIntyre, ao contrário, sustenta que vivemos em um mundo com valores morais objetivos. Do ponto-de-vista linguístico. No mundo de Mackie, o uso da linguagem moral é baseado na crença (falsa) na objetividade dos valores morais. No mundo de MacIntyre, ao contrário, o uso da linguagem moral é baseado na crença (falsa) na subjetividade dos valores morais.

\section{O mundo sem valores morais objetivos de Mackie}

Hare, em 'Nothing Matters' - que possui o sugestivo subtítulo de Is 'the Annihilation of Values' something that could happen? - sugere que não existem diferenças éticas fundamentais entre um mundo, no qual os valores morais são objetivos, e outro mundo, no qual os valores morais são subjetivos:

Pense em um mundo em cuja estrutura os valores sejam objetivamente fundamentados; e pense em outro no qual esses valores tenham sido aniquilados. E lembre que em ambos 
os mundos as pessoas continuam interessadas nas mesmas coisas - não existe diferença no interesse 'subjetivo' que as pessoas possuem pelas coisas, apenas em seu valor 'objetivo'. Agora eu pergunto, Qual é a diferença entre o estado das coisas nesses dois mundos? Alguma outra resposta pode ser dada exceto 'Nenhuma, qualquer que seja'? Como, portanto, podemos nos atormentar com dúvidas acerca de com qual deles nosso próprio mundo se parece? (HARE, 1972, p. 47)

Mackie, em Ethics Inventing the Right and Wrong, discorda das conclusões desse argumento de Hare. Hare postula a indiferença entre um mundo, no qual os valores sejam baseados objetivamente na estrutura do mundo, e outro, no qual eles sejam instituídos de forma absolutamente arbitrária ou subjetiva. Para Mackie, o raciocínio de Hare possui implicações lógicas e não ontológicas. Mackie afirma que a inexistência de uma diferença relevante, no que concerne aos interesses subjetivos dos agentes, entre esses dois mundos. Implica, unicamente, no reconhecimento da distinção lógica entre juízos de primeira ordem (juízos morais materiais, determinando quais ações particulares são "boas") e segunda ordem (juízos sobre a natureza ética da "bondade"). Para Mackie, Hare está apontando simplesmente para a distinção lógica entre juízos morais materiais particulares e juízos éticos e metaéticos. Mackie afirma que "não é verdadeiro que não exista nenhuma diferença, qualquer que seja, entre esses dois mundos. Em um existe algo que fundamenta e valida alguns dos interesses subjetivos que as pessoas possuem pelas coisas e no outro não" (MACKIE, 1990, p. 22). Mackie delineia a diferença ontológica relevante entre esses dois mundos:

Se existisse algo na estrutura do mundo que validasse certos tipos de interesses, então seria possível adquiri-los meramente descobrindo-os, permitindo que o pensamento fosse controlado pelo modo como as coisas são. Mas no mundo em que valores objetivos tenham sido aniquilados a aquisição de algum novo interesse subjetivo significaria o desenvolvimento de algo novo no lado emotivo da pessoa que o adquirisse algo que os escritores do século dezenove colocariam sob a título de paixão ou sentimento. (MACKIE, 1990, p. 22)

Mackie, em Ethics Inventing the Right and Wrong, expõem as características gerais de seu ceticismo ético. Reivindi- 
cando, basicamente, que não existem valores morais objetivos. Mackie sugere que valores não compõem o tecido (a estrutura) do mundo. Não possuindo, por essa razão, objetividade ontológica. Para Mackie, valores não podem ser incluídos entre os itens realmente existentes no mundo. Não podendo, dessa forma, ser objetos de discursos, juízos ou declarações puramente descritivos. Mackie afirma que valores não fazem parte da realidade empírica do mundo:

A reivindicação de que valores não são objetivos, não sendo parte do tecido do mundo, inclui não apenas a bondade moral, que poderia mais naturalmente ser equiparada com valores morais, mas também outras coisas que podem mais imprecisamente ser denominados valores ou desvalores morais - correção e erro, dever, obrigação e ações consideradas vis ou desprezíveis, e assim por diante [...] Desde que é com valores morais que estou primariamente interessado, a visão que estou adotando pode ser denominada ceticismo moral. (MACKIE, 1990, pp. 15-16)

O ceticismo moral, proposto por Mackie, constitui, basicamente, uma tese ontológica negativa. Mackie postula, fundamentalmente, o que valores morais não são. Reivindicando que eles não constituem entidades ou relações naturais que compõem o tecido do mundo. Concluindo, por essa razão, que não possuem "objetividade" ontológica. Mackie adverte que seu ceticismo moral não deve ser confundido com uma espécie de subjetivismo moral positivo. Baseado em análises conceituais ou linguísticas, que procuram elucidar o significado das declarações morais. Ressaltando, igualmente, a diferença de sua teoria ética em relação ao emotivismo, isto é, a teoria que postula que juízos morais constituem meras expressões dos sentimentos e atitudes dos agentes. Essa ressalva se justifica porque o emotivismo representa uma teoria positiva, que procura determinar o que são os juízos morais. Mackie, ao contrário, admite que valores morais possam ser escolhidos e defendidos racionalmente. Mackie reconhece que valores morais são extremamente úteis racionalmente para as relações humanas. Sendo originados através de convenções e instituições sociais e culturais, historicamente determinadas. Mackie estabelece um vínculo filosófico entre seu ceticismo ontológico e sua teoria do erro: 
Primeiro, o que tenho denominado ceticismo moral é uma doutrina negativa, não uma positiva: ela diz o que não existe, não o que existe. Diz que não existem entidades ou relações de certo tipo, valores ou requerimentos objetivos, que muitas pessoas acreditam existirem. É claro, o cético moral não pode deixar isso assim. Se sua posição é para ser plausível como um todo, ele precisa oferecer alguma explicação de como outras pessoas têm incorrido naquilo que ele considera como um erro e essa explicação terá de incluir algumas sugestões positivas sobre como os valores falham em ser objetivos, sobre o que tem sido compreendido equivocadamente, ou conduzido a crenças falsas, sobre valores objetivos. Mas isso será um desenvolvimento de sua teoria, não o seu núcleo: seu núcleo é a negação. Segundo, o que tenho denominado ceticismo moral é uma tese ontológica, não linguística ou conceitual (MACKIE, 1990, pp. 17-18).

Mackie ressalta a natureza ontológica de seu ceticismo moral, enfatizando que sua teoria se concentra numa análise factual da moralidade:

Mas também existem questões ontológicas, em contraste com linguísticas e conceituais, acerca da natureza e estado da bondade ou justiça [...]. Essas são questões de análise factual ao invés de conceitual: o problema acerca do que a bondade é não pode ser estabelecido conclusivamente ou exaustivamente pela descoberta do que significa a palavra 'bom' [...] (MACKIE, 1990, p. 19).

Visando enfatizar a natureza ontológica de sua análise filosófica. Mackie propõe uma analogia entre o status ontológico dos valores morais e a teoria epistemológica de Locke a respeito das "qualidades primárias e secundárias" dos objetos da percepção (LOCKE, 1999, pp. 116-125). Locke, em An Essay Concerning Human Understanding, capítulo II, seção VIII, sugere a existência de uma distinção ontológica entre "qualidades primárias" e "qualidades secundárias". Qualidades primárias correspondem às propriedades puramente físicas (ou moleculares) dos objetos. Enquanto, qualidades secundárias são produzidas, basicamente, pela impressão que essas "qualidades primárias" produzem nas superfícies sensoriais que captam e interpretam os fótons por elas refletidos. Locke sugere que as cores constituem "qualidades secundárias" dos objetos empíricos. Desse modo, as "cores", como as percebemos, não 
pertencem, intrinsecamente, às qualidades primárias dos objetos. Cores não compõem a estrutura molecular dos objetos empíricos, constituindo um fenômeno ótico causado pela percepção sensorial da reflexão da luz na superfície desses objetos. Os objetos empíricos não são azuis ou vermelhos em si mesmo, apenas são percebidos como tais pelos órgãos sensoriais humanos. Do ponto de vista puramente físico. A forma como percebemos as cores é produzida pelo comprimento das ondas de luz, refletidas pelo tipo de estrutura molecular da superfície dos objetos materiais, que atingem nossos órgãos sensoriais. Dessa maneira, as "cores" somente são percebidas como tais em razão da constituição biológica dos seres humanos, e não, diretamente, pela constituição física dos objetos em si mesma. Outros animais, por exemplo, percebem as cores dos mesmos objetos de maneira diferente do que os humanos. Variações na luminosidade, deficiências na visão ou nas partes do cérebro responsáveis pela interpretação das cores, tais como o daltonismo, alteram a forma como diferentes indivíduos percebem cores. Ainda que as características puramente físicas ou moleculares dos objetos percebidos não apresentem qualquer variação. Mackie sugere que valores morais, tal como as "cores", também não constituem "qualidades primárias" do mundo. Sendo equivalentes, mais precisamente, às "qualidades secundárias". Para Mackie, valores morais dependem, fundamentalmente, da percepção subjetiva dos agentes morais. Sendo determinados, basicamente, por suas escolhas, ideais, finalidades e tradições morais. Mackie postula que a "existência" dos valores morais depende, essencialmente, da interpretação subjetiva que acrescentamos - através dos juízos, conceitos, termos, argumentos e discursos morais - às características empíricas objetivas das circunstâncias e das ações. Mackie acredita que somente essas características empíricas das ações possuem existência objetiva, fazendo parte do tecido do mundo. Mackie sustenta que somente as "qualidades primárias" (características empíricas dos objetos ou fatos) possuem objetividade ontológica. Enquanto, as "qualidades secundárias" (cores ou valores morais) possuem unicamente natureza epistemológica ou conceitual. Mackie propõe essa analogia para distinguir seu ceticismo moral, funda- 
mentado em uma análise ética de natureza ontológica, que investiga a natureza intrínseca dos valores morais, de análises éticas de natureza linguística ou conceitual, que investigam o significado dos conceitos, termos que constituem a linguagem moral. Sugerindo que uma análise conceitual ou linguística concluirá necessariamente que valores morais, como cores, são objetivos (possuem referência racionalmente válida a convenções sociais, por exemplo) para os agentes que os enunciam, embora não façam parte da estrutura do mundo. Através dessa analogia, Mackie procura explicar algumas características fundamentais de sua célebre "teoria do erro". Especialmente, a forma como ocorre o "erro" da atribuição, pelo senso comum, de objetividade aos valores morais. Afirmando que esse erro é causado por uma confusão entre o uso e o significado da linguagem e dos conceitos morais e a realidade empírica da estrutura do mundo. Mackie adverte que uma análise ética, puramente linguística ou conceitual, não seria capaz de revelar esse grave equívoco, mas somente uma análise ética ontológica ou metafísica. O ceticismo moral de Mackie procura desenvolver essa investigação metafísica, constituindo uma teoria de ontologia moral. McDowell oferece uma consistente análise crítica acerca dessa analogia de Mackie em "Values and Secondary Qualities" (MCDOWELL, 2002, pp. 131-150). Mackie sugere que a objetividade atribuída aos valores morais em nossa cultura é semelhante ao que Hume postula como a propensão da mente de espalhar-se sobre os objetos externos:

Em uma visão subjetivista, valores supostamente objetivos serão baseados de fato nas atitudes que a pessoa adota considerando estar reconhecendo e respondendo a esses valores. Se admitirmos o que Hume denomina da "propensão da mente de espalhar-se sobre os objetos externos" podemos entender a suposta objetividade das qualidades morais como surgindo de algo que poderíamos denominar de projeção ou objetivação das atitudes morais. (MACKIE, 1990, p. 42)

Mackie sugere que os juízos morais, ordinariamente proferidos pelas pessoas comuns, na cultura ocidental, pressupõem, erroneamente, a existência de valores objetivos. E que essa atribuição de objetividade aos valores éticos constitui um compromisso ontológico fundamental. Assumido, tanto pelo 
senso comum, como pela parcela majoritária da filosofia moral ocidental, desde a Grécia Clássica até a contemporaneidade. Sugerindo que essa crença ontológica acerca da natureza prescritiva objetiva dos valores éticos foi amplamente disseminada em nossa cultura. Tendo sido fortemente incorporada pela semântica da linguagem moral ordinária. Passando, dessa forma, a constituir um elemento indissociável do significado convencional básico de todos os conceitos e termos empregados nos discursos morais em geral. Mackie sugere que esse entrincheiramento ontológico e linguístico da crença na objetividade dos valores morais é uma característica fundamental da cultura ocidental. Constituindo a principal razão, pela qual, análises conceituais e linguísticas são ineficazes para evidenciar a verdadeira natureza subjetiva dos valores morais:

Se uma ética de segunda ordem estiver confinada, então, a análises conceituais e linguísticas, ela deveria concluir que valores morais são ao menos objetivos: que eles são assim é parte do que nossas declarações morais ordinárias significam: os conceitos morais tradicionais do homem comum tanto quanto da principal vertente dos filósofos ocidentais são conceitos de valor objetivo. Mas é precisamente por essa razão que a análise conceitual e linguística não é suficiente. (MACKIE, 1990, p. 35)

Mackie sustenta que o ceticismo moral somente pode ser formulado adequadamente como resultado de uma "teoria do erro":

A reivindicação de objetividade, apesar de estar entranhada em nosso pensamento e linguagem, não é auto-justificada (validada). Ela pode e deve ser questionada. Mas a negação da objetividade dos valores terá de ser formulada não como o resultado de uma abordagem analítica, mas como uma "teoria do erro", uma teoria de que apesar de que a maioria das pessoas ao realizar juízos morais reivindica, entre outras coisas, estarem apontando para algo objetivamente prescritivo, essas reinvindicações sã̃o todas falsas. É isso que torna o nome "ceticismo moral" apropriado. (MACKIE, 1990, p. 35)

Mackie afirma que a aceitação generalizada da "teoria do erro" requer uma argumentação consistente. Porque a suposição da objetividade dos valores morais encontra-se solidamente enraizada no senso comum ocidental. Refletindo-se 
amplamente na linguagem e nos conceitos morais empregados na vida cotidiana. Ressaltando que a teoria do 'erro' contraria "presunções entranhadas em nosso pensamento, que são expressas em alguns modos nos quais a linguagem é usada, desde que conflita com o que, às vezes, é chamado senso comum" (MACKIE, 1990, p. 35). O ponto filosófico essencial é que a "teoria do erro" de Mackie constitui, basicamente, uma teoria de natureza linguística, analisando o uso da linguagem moral na sociedade ocidental. Sua tese fundamental consiste na reivindicação de que o uso da linguagem moral tradicional, pelas pessoas em geral na sociedade ocidental, é baseado em um 'erro' ontológico fundamental. Consistente na atribuição de validade objetiva ou imperatividade absoluta aos juízos, discursos, conceitos e termos morais em geral. Mackie sustenta, ao contrário, que os valores morais, expressos através dessa linguagem, não possuem objetividade ontológica. Por não fazerem parte da estrutura do mundo. Mackie afirma que valores morais não são universais e necessários. Não possuindo, por essa razão, natureza ontológica prescritiva ou imperativa absoluta. Para Mackie, a "existência" dos valores morais depende das crenças, desejos e inclinações dos agentes. Mackie reivindica, portanto, que valores morais possuem natureza subjetiva (e intersubjeti$v a)$, contingente, social e cultural:

Atitudes morais em si mesmo são ao menos parcialmente sociais na origem: socialmente estabelecidas - e socialmente necessárias - padrões de comportamento põem pressão sobre os indivíduos e cada indivíduo tende a internalizar essas pressões e a associar-se em requerer esses padrões de comportamento de si mesmos e dos outros. As atitudes que são objetivadas em valores morais possuem realmente uma fonte externa, apesar de não ser aquela atribuída pela crença em sua autoridade absoluta. Sobretudo, existem motivos que poderiam apoiar essa objetivação. Necessitamos da moralidade para regular as relações interpessoais, controlar os modos pelos quais as pessoas se comportam umas em relação às outras, frequentemente em oposição a inclinações contrárias. Assim sendo, nós queremos que nossos juízos morais sejam autoritários para os outros agentes assim como para nós mesmos: validade objetiva poderia conferir a eles a autoridade requerida. (MACKIE, 1990, pp. 41-42) 
Mackie sugere que juízos morais não são logicamente cogentes. Nem constituem imperativos racionais universais e necessários. Mackie acredita que juízos e valores morais unicamente refletem ou projetam no mundo as opções, preferências, desejos, interesses ou finalidades subjetivas dos agentes:

Outro modo de tentar esclarecer esse assunto refere-se ao raciocínio moral e aos argumentos morais. Na prática, é claro, tal raciocínio é raramente completamente explícito: mas deixe-nos supor que pudéssemos tornar explícitos os raciocínios que sustentam alguma conclusão valorativa, onde essa conclusão possua certa força diretiva da ação que seja contingente aos desejos ou propósitos ou fins escolhidos. Então o que estou dizendo é que em algum lugar na estrutura desse argumento - talvez em uma ou mais das premissas, talvez em alguma parte da forma do argumento - haverá algo que não pode ser validado objetivamente - alguma premissa que não é capaz de ser simplesmente verdadeira, ou alguma forma do argumento que não é válida como matéria de lógica geral, cuja autoridade ou cogência não é objetiva, mas é constituída por nossa escolha ou decisão de pensar de certa maneira. (MACKIE, 1990, pp. 29-30)

Mackie reivindica que, na estrutura do raciocínio ético e da justificação dos juízos morais, sempre estão presentes, necessariamente, premissas "subjetivas". Premissas subjetivas, para Mackie, são caraterizadas, basicamente, por refletirem escolhas, racionais ou irracionais, do agente. Não sendo objetivas, porque não se referem a nenhuma parte integrante da estrutura do mundo. Essas premissas também são consideradas subjetivas porque não podem ser demonstradas logicamente. Nem constituem imperativos racionais universais e necessários. Dessa forma, todo o raciocínio moral possui premissas éticas que não possuem os atributos ontológicos fundamentais, universalidade e necessidade. Mackie afirma que valores morais não possuem o mesmo tipo de objetividade ontológica dos "fatos empíricos" em geral. Por essa razão, valores éticos não podem ser objetos de um discurso puramente descritivo, já que não fazem parte do tecido do mundo ou da realidade. Subscrevendo, dessa forma, a tese da dicotomia fato/valor, típica do Positivismo Lógico e de parcela majoritária da Filosofia Analítica. Mackie afirma que todo o valor moral se resume a uma resposta subjetiva às características empíricas de uma 
circunstância. Reivindicando que essas circunstâncias factuais, por sua vez, não possuem em si mesmas, nenhum valor moral intrínseco. Dessa maneira, Mackie sustenta que o ato de torturar uma criança, por exemplo, obviamente, e necessariamente, possui características naturais ou factuais que implicam no conceito de crueldade. Ressalvando, porém, que o juízo de reprovação moral não decorre necessariamente dessas características empíricas naturais da situação. Mackie reivindica que a adição do discurso e do juízo moral é subjetiva. Não acrescentando nenhuma nova qualidade ou característica ontológica relevante ao fato. Para Mackie, todo o valor está fora do mundo, conforme a famosa metáfora de Wittgenstein:

Esses tipos de comportamento para os quais são atribuídos valores e desvalores morais são realmente parte do mobiliário do mundo, e, portanto, existem diferenças naturais, descritivas, entre eles; mas não, talvez, diferenças em valor. É um fato inquestionável que ações cruéis diferem de generosas, e, consequentemente, que podemos aprender, como de fato nós todos aprendemos, a distingui-las na prática razoavelmente bem, e a usar as palavras 'cruel' e 'generoso' com significados descritivos razoavelmente claros; mas seria também um fato igualmente inquestionável que ações cruéis nesse sentido descritivo devem ser condenadas? A presente questão é em relação especificamente à objetividade do valor, não se referindo a objetividade dessas diferenças naturais, factuais, com base nas quais diferentes valores são atribuídos. (MACKIE, 1990, pp. 16-17)

Um aspecto fundamental do ceticismo moral de Mackie consiste na distinção entre o status ontológico das noções de "objetividade" e de "intersubjetividade":

A questão da objetividade dos valores necessita, entretanto, ser distinguida de outras com as quais poderia ser confundida. Dizer que existem valores objetivos não seria meramente dizer que existem certas coisas que são valorizadas por todos, nem está implicado nisso. Poderia existir acordo na valoração mesmo se a valoração fosse apenas algo que as pessoas fazem, mesmo se essa atividade não fosse validada. Acordo subjetivo poderia fornecer valores intersubjetivos, mas intersubjetividade não é objetividade. (MACKIE, 1990, p. 22)

Mackie reivindica manifestamente que "intersubjetividade não é objetividade". Mackie reconhece que a atividade de 
valoração faz parte da natureza humana. Admitindo que valores morais possuam justificação racional, social e ou cultural. Mackie atribui propriedades filosóficas diferentes às noções de objetividade e de intersubjetividade. Reivindicando que valores morais podem possuir validade, meramente, intersubjetiva. Para Mackie, uma justificação intersubjetiva não atribui status ontológico aos valores morais. Nesse sentido, Mackie parece crer que convenções sociais ou culturais não fazem parte da estrutura do mundo:

É claro, dirão alguns, valorar, preferir, escolher, recomendar, rejeitar, condenar, e assim por diante, são atividades humanas, e não há necessidade de procurar por valores que sejam anteriores a e logicamente independentes a todas essas atividades. Pode de fato haver um acordo disseminado sobre a valoração, e juízos de valor particulares em geral não são arbitrários ou isolados: eles são tipicamente coerentes uns com os outros, ou podem ser criticados se não forem, razões podem ser oferecidas em seu favor, e assim por diante: mas se tudo o que o subjetivista está sustentando é que desejos, fins, propósitos, e coisas semelhantes, figuram em alguma parte do sistema de razões, e que fins e propósitos não são objetivos em oposição a ser meramente intersubjetivos, então isso, pode ser concedido sem muito problema. (MACKIE, 1990, p.30)

Mackie adota uma espécie de ontologia fisicalista ou materialista, típica do Empirismo Clássico e do verificacionismo do Positivismo Lógico. Considerando que apenas objetos "físicos" ou "materiais", perceptíveis pelos órgãos sensoriais, possuem existência genuína ou status ontológico. Reivindico que essa ontologia materialista, implica, necessariamente, na pressuposição da correção da tese da dicotomia fato/valor. A ideia de uma dicotomia ontológica fato/valor possui origem filosófica na distinção proposta por Hume, em A Treatise of Human Nature (HUME, 1978, pp. 463-469), entre "juízos de fato" e "relações de ideias" (equivalentes, nesse contexto, a "juízos de valor"). Hume postula uma dicotomia ontológica e epistemológica radical entre "fatos" e "valores". Reivindicando que (a) fatos podem ser objetos de discursos puramente descritivos, valores não; (b) fatos podem ser verificados empiricamente, valores não; (c) fatos podem ser objetos de acordo racional, valores não; (d) fatos podem ser considerados logicamente e 
materialmente verdadeiros ou falsos, enquanto valores não são passíveis de juízos lógicos disjuntivos de verdade e falsidade. Dessa forma, a "teoria do erro" implica numa rejeição dogmática de qualquer tipo de ontologia social ou cultural. As implicações filosóficas mais amplas, da adoção dessa ontologia fisicalista por Mackie, serão analisadas pormenorizadamente mais adiante. Quando cotejarmos as diferenças mais relevantes entre as ontologias morais propostas por Mackie e MacIntyre. Mackie, como Hume, acredita que os valores morais, que compõem o sistema holístico de crenças, que consubstancia uma cultura ou tradição moral, particular e contingente, não possuem existência factual ou status ontológico. Para Mackie, valores morais não compõem o tecido do mundo, ou numa linguagem epistemológica, não refletem o mundo como ele realmente é "em si mesmo". Mackie aponta as principais razões em favor de seu ceticismo moral: (1) o relativismo moral. Valores morais são contingentes, dependendo de formas de vida ou tradições culturais historicamente localizadas. De modo que o raciocínio moral assume diferentes premissas ou princípios conforme a realidade social de uma comunidade humana específica; (2) a esquisitice metafísica e epistemológica dos valores morais. Do ponto de vista metafísico. Valores morais constituem entidades ou relações ontológicas, absolutamente diferentes de todas as outras reconhecidamente existentes no mundo. Do ponto de vista epistemológico. A possibilidade do conhecimento de valores morais implicaria na necessidade da existência de alguma faculdade cognitiva ou forma de percepção ou intuição moral específica, capaz de reconhecê-los. Uma faculdade diferente de todos os meios ordinariamente admitidos para a obtenção de conhecimento sobre o mundo; (3) a inexistência de uma explicação satisfatória acerca da forma como os valores morais podem ser consequentes ou supervenientes às características naturais de uma situação factual. Ou seja, a dificuldade de explicar adequadamente qual espécie de relação ontológica existiria entre os fatos empiricamente observados e os valores morais a eles atribuídos. (Mackie propõe que a explicação mais convincente seria que essa relação reside em uma resposta subjetiva do agente. Causalmente consequente ao reconhecimento das 
condições empíricas de uma situação); (4) a existência de diferentes padrões de objetivação. Na medida, que existem diferentes abordagens teóricas que sustentam a crença na objetividade dos valores. Paixões e desejos do agente, legislação Divina, sistema de leis (do qual Deus foi removido), convenções morais socialmente válidas, interesses e demandas dos agentes, constituem alguns desses padrões propostos. Outros, ainda, apontam para a internalização psicológica dos valores pelos agentes, que se reflete ou se objetiva através do comportamento ou da identidade moral. Mackie admite que juízos morais possam ser objetivos quando referidos a determinados padrões convencionalmente aceitos. Mas argumenta que, nesse caso, a atribuição da subjetividade aos valores morais, simplesmente é transferida para a escolha entre esses diferentes padrões. Para Mackie, essa escolha não está submetida a qualquer validade objetiva, dependendo de opções relativamente arbitrárias dos agentes; e, finalmente, (5) valores morais não constituem imperativos categóricos, capazes de determinar ações de maneira absoluta e objetiva. Em razão de que sua natureza imperativa é contingentemente determinada. Makie conclui que a justificação e a imperatividade dos valores morais é necessariamente subjetiva e relativa. Reivindicando que valores morais expressam formas culturais, sistemas de crenças, desejos, escolhas, inclinações e ou finalidades dos agentes.

\section{O mundo com valores morais objetivos de MacIntyre}

MacIntyre, em After Virtue: A Study on Moral Theory, sustenta que o constante, e aparentemente interminável, desacordo moral, verificado na sociedade ocidental contemporânea, é resultado de um processo histórico. Postulando que esse processo contingente produziu uma desorganização na linguagem e nos conceitos empregados nos juízos, argumentos e discursos morais. MacIntyre acredita que as causas que ensejaram essa ausência de padrões morais amplamente compartilhados. Capazes de oferecer soluções para as controvérsias morais recorrentes em nossa cultura pós-moderna. Somente podem ser adequadamente compreendidas mediante uma análise históri- 
ca e sociológica. MacIntyre sugere que as causas desse desacordo moral pós-moderno derivam da forma como as tradições morais antigas e medievais foram, inicialmente, descartadas. E, posteriormente, substituídas, pelas concepções morais tipicamente modernas. MacIntyre afirma que a moralidade ocidental entrou em um estado de desordem como resultado dessa transição histórica. MacIntyre postula, fundamentalmente, que, nesse processo histórico, a moralidade ocidental foi privada do contexto social que lhe conferia inteligibilidade e imperatividade. Para MacIntyre, quando as estruturas sociais, características da antiguidade e do medievo, foram destruídas e substituídas pelas formas sociais da modernidade. A linguagem e os conceitos característicos das tradições morais dessas culturas antecedentes - baseadas, principalmente, na ética aristotélica, predominante desde a Grécia Clássica até a Escolástica, e na justificação teológica da idade média - permaneceram sendo utilizados pela sociedade moderna e pós-moderna. Constituindo uma herança cultural que continuou entrincheirada nos juízos e discursos morais. Dessa forma, a linguagem que expressa essas desavenças, aparentemente insolúveis, da moralidade contemporânea, reflete conceitos morais formulados por essas tradições passadas. Conceitos esses, que deslocados de seu contexto histórico e social original, tornaram-se disfuncionais. Perdendo a capacidade de produzir um acordo social mínimo acerca de questões morais fundamentais. O ponto é que, para MacIntyre, uma das causas mais relevantes do desacordo moral contemporâneo consiste na ausência de uma noção de "racionalidade" amplamente compartilhada pelos protagonistas do debate moral. As controvérsias contemporâneas não podem ser resolvidas racionalmente, porque os contendores adotam premissas oriundas de diferentes tradições morais em seus argumentos. De modo, que cada um desses argumentos, embora contraditórios entre si, são plenamente válidos do ponto de vista lógico. Isso ocorre, conforme MacIntyre, porque a própria noção de "racionalidade" constitui uma construção cultural histórica e contingente. De modo, que aquilo que é considerado "racional" em uma tradição moral pode ser considerado "irracional" em outra. Para MacIntyre, a justificação racional dos valores morais não é trans- 
cendental e absoluta. Na medida, que a noção de "racionalidade" é parte de um sistema de crenças holístico mais amplo, que determina nosso juízo, tanto do que é "racional", como do que é "moral". O aspecto fundamental consiste em que MacIntyre acredita que valores morais somente possuem racionalidade no "interior" de um sistema holístico de crenças contingente. De modo, que somente podem ser justificados racionalmente para aqueles agentes que previamente compartilham desse mesmo sistema doxástico. MacIntyre sugere que valores morais são contingentes, e, portanto, não constituem verdades a priori. Dessa forma, valores morais devem ser construídos através da pesquisa racional. MacIntyre adota uma postura falibilista em relação à justificação da moralidade. Sugerindo que valores morais devem ser construídos racionalmente. Esse falibilismo implica em que todo e qualquer valor moral pode ser aperfeiçoado através da investigação racional. MacIntyre conclui que o desacordo moral contemporâneo está profundamente enraizado na cultura ocidental. Delineando os aspectos culturais mais relevantes desse processo histórico e social:

Essa cultura continua a ser uma na qual os desacordos morais e outros nos quais os enunciados valorativos e normativos das partes contendoras apresentam um problema de intepretação, continuam sem solução e são aparentemente insolúveis. Por um lado, eles parecem pressupor uma referência a algum padrão impessoal compartilhado, em virtude do qual, no máximo uma dessas partes contendoras pode estar certa, e por outro lado, a pobreza dos argumentos aduzidos em apoio as suas asserções e o modo assertivo e expressivo, caracteristicamente estridente, nos quais são enunciados, sugerem fortemente que esse padrão não existe. (MACINTYRE, 2007, p. ix)

MacIntyre sugere uma explicação para o fenômeno do desacordo moral ocidental:

Minha explicação foi e é a de que os preceitos que são assim enunciados foram familiares, e inteligíveis em termos de, apoiados em um contexto de crenças práticas e hábitos de pensamento, sentimento, e ação, um contexto que foi perdido desde então, um contexto no qual juízos morais eram entendidos como sendo governados por padrões impessoais justificados por uma concepção compartilhada do bem humano. Privado desse contexto e dessa justificação, como resul- 
tado de mudanças sociais e morais transformadoras e perturbadoras na idade média tardia e no novo mundo moderno, leis e preceitos morais tiveram de serem entendidas de novas maneiras, mediante a atribuição de algum novo status, autoridade e justificação (MACINŢYRE, 2007, pp. ix-x).

MacIntyre conclui que esse processo de transformações históricas e sociais da sociedade ocidental produziu uma cultura moral tipicamente emotivista. Na qual, os juízos e o raciocínio moral perderam seus padrões de objetivação. Dessa forma, todas as premissas da justificação moral passaram a ser interminavelmente contestáveis. De modo, que o senso comum passou a considerá-los como meras expressões dos sentimentos e atitudes dos agentes que os enunciavam. O ponto é que, apesar dessa ausência de padrões impessoais e objetivos compartilhados. A linguagem e os juízos morais permaneceram sendo enunciados através de expressões e termos imperativos. Como se se referissem a padrões impessoais, que permitissem uma solução racional consensual para os conflitos morais. Embora esses conflitos, na verdade, se referissem não apenas a justificação, como ao conteúdo material da moralidade. MacIntyre sustenta que o significado dos enunciados valorativos e dos principais conceitos que empregamos usualmente na linguagem da moralidade, sofreu alterações radicais nos últimos três séculos. E que, como resultado dessa evolução, conceitos como 'virtude', 'justiça', 'piedade', 'dever' e 'obrigação', ao serem deslocados de seu contexto social e histórico tradicional, perderam seu significado original na cultura moral contemporânea. MacIntyre sugere que, nesse processo de transformação histórica e social, a linguagem e os conceitos morais passaram de um estado de ordem para um estado de desordem. Ao serem privados dos contextos de teoria e prática para os quais foram concebidos. $\mathrm{E}$, para os quais, eram adequados e plenamente funcionais. No estado de ordem da moralidade, a linguagem moral permitia um acordo moral mínimo nas sociedades antigas e medievais. O estado de desordem atual da moralidade ocidental, porém, impede a obtenção de um consenso moral mínimo:

Porque se eu estou certo em supor que a linguagem da moralidade passou de um estado de ordem para um estado de 
desordem, essa passagem será obviamente refletida - e realmente consistirá em - nessas mudanças de significado. Sobretudo, se as características que identifiquei em nossos próprios argumentos morais - mais notavelmente o fato de que tratamos o argumento moral simultaneamente e inconsistentemente como exercício de nossos poderes racionais e meras asserções expressivas - são sintomas de desordem moral, devemos estar aptos a construir uma narrativa histórica verdadeira de um estágio anterior no qual o argumento moral era de uma espécie muito diferente (MACINTYRE, 2007, p. 11).

Conforme a narrativa histórica proposta por MacInyre. A principal causa filosófica da desorganização da linguagem moral na sociedade contemporânea consiste no abandono da tradição ética aristotélica. MacIntyre sugere que a modernidade descartou tanto a justificação teleológica da moralidade, típica do aristotelismo, como a justificação teológica, típica da tradição medieval. Sem que um novo tipo de justificação moral consistente tenha sido formulado. Esse processo culminou com a crença, disseminada na sociedade ocidental, de que o emotivismo constitui uma teoria ética verdadeira. MacIntyre reivindica que o processo de desorganização da cultura moral na sociedade ocidental apresentou três estágios distintos: (1) um estágio no qual a teoria e a prática moral são fundamentadas em padrões impessoais e objetivos, racionalmente justificáveis. Padrões esses que garantem, por sua vez, uma justificação igualmente racional dos juízos e ações morais particulares; (2) um estágio intermediário, no qual ocorrem tentativas, continuamente frustradas, de garantir uma justificação racional da moralidade. Através da proposição de novos padrões racionais e impessoais que permitam a formulação de juízos morais objetivos. Todos esses novos padrões morais propostos, porém, mostram-se incapazes de produzir um acordo moral racional, minimamente satisfatório. Como resultado, o projeto moderno de justificação racional da moralidade, finalmente, entra em descrédito; (3) um estágio final, no qual as teorias morais emotivistas são incorporadas pelo senso comum. Em razão da descoberta filosófica moderna, amplamente disseminada, acerca da subjetividade ontológica da moralidade. De modo, que os valores e juízos morais perdem completamente sua objetividade e impessoalidade. Essa cultura emotivista se torna implícita nos 
discursos e nas práticas morais cotidianas das pessoas comuns. Embora não seja admitida, explicitamente, na teoria ética. A partir do esquema histórico delineado, que demonstra os estágios da transição entre uma moralidade funcional e uma moralidade desordenada. MacIntyre extrai conclusões fundamentais, acerca, tanto da objetividade e racionalidade dos valores morais, como da disseminação do emotivismo na sociedade e na cultura ocidental:

A própria afirmação desse esquema é suficiente para sugerir que as reivindicações gerais do emotivismo, reinterpretado como teoria do uso não podem ser postas de lado tã̃o facilmente. Porque uma pressuposição do esquema de desenvolvimento que acabei de esboçar é que genuínos padrões morais impessoais e objetivos podem, de uma maneira ou de outra, ser racionalmente justificados, ainda que em certos estágios de algumas culturas a possibilidade dessa justificação racional não esteja mais disponível. E isso é o que o emotivismo nega. O que tenho sugerido ser o caso acerca de nossa própria cultura - que no argumento moral a asserção aparente de princípios funciona como uma máscara para expressões de preferências pessoais - é o que emotivismo considera ser universalmente o caso. E acima de tudo, o faz em bases que não requerem nenhuma investigação histórica ou sociológica em geral das culturas humanas. Porque o que o emotivismo afirma é na parte central que não existem e nem podem existir justificação racional válida para nenhuma reivindicação de que existam padrões morais impessoais e objetivos e que, portanto, esses padrões não existem [...] Então o emotivismo sustenta que pretensas justificações racionais podem existir, mas justificações racionais reais não podem existir, porque não existe nenhuma. (MACINTYRE, 2007, p. 19)

MacIntyre reivindica que o emotivismo está completamente errado, enquanto teoria do significado dos termos morais. Mas permanece plausível, enquanto teoria do uso da linguagem moral. Ressaltando que as consequências práticas da crença disseminada amplamente em nossa sociedade, a respeito da correção do emotivismo. São mais perturbadoras do que as consequências do reconhecimento teórico de sua natureza verdadeira enquanto teoria ética geral. Para MacIntyre, do ponto de vista linguístico, o emprego da expressão 'eu desaprovo isso', ao invés de 'isso é mau', produz consequências morais diferentes. Porque o uso de enunciados, tais como 'isso é justo' ou 'isso 
é injusto', implica, implicitamente, num apelo a padrões morais impessoais e objetivos. Apelo esse, que expressões como 'desaprovo isso, desaprove também', não possuem. Dessa forma, se o emotivismo for verdadeiro. E, portanto, a crença disseminada em sua correção for justificada. A linguagem moral herdada das culturas ocidentais anteriores, concebida originalmente de forma imperativa, tornou-se ininteligível e disfuncional, no contexto da sociedade pós-moderna. De modo, que seu uso deve ser completamente abandonado. MacIntyre sustenta que a própria noção de racionalidade, por si mesma, oferece base suficiente para a justificação objetiva da moralidade. Fornecendo os fundamentos para a rejeição, tanto do emotivismo, como de todas as outras formas de subjetivismo moral. MacIntyre conclui que o emotivismo se incorporou fortemente no senso comum da sociedade ocidental contemporânea. Embora não seja verdadeiro enquanto teoria ética universal e necessária: "em larga escala as pessoas agora pensam, falam e agem como se o emotivismo fosse verdadeiro [...] O emotivismo tornou-se incorporado em nossa cultura" (MACINTYRE, 2007, p. 22). Sugerindo que essa crença generalizada no emotivismo constitui um traço cultural que determina as características mais relevantes da moralidade pós-moderna:

Porque tenho sugerido que vivemos em uma cultura especificamente emotivista, e se isso é assim presumivelmente devemos descobrir que uma ampla variedade de nossos conceitos e modos de comportamento - e não apenas nossos debates e juízos morais explícitos - pressupõe a verdade do emotivismo, se não ao nível da teorização autoconsciente, ao menos na prática diária (MACINTYRE, 2007, p. 22).

MacIntyre sugere que o eu emotivista é resultado do tipo de ordem social vigente no Ocidente contemporâneo, se expressando através dos papéis sociais dominantes. Ressaltando que o desacordo moral contemporâneo decorre, em larga medida, do descrédito generalizado na possibilidade de uma justificação racional da moralidade:

O que apontei anteriormente como um ponto de vista distintivamente moderno, foi a concepção do debate moral em termos de uma confrontação entre premissas morais e com- 
promissos morais incompatíveis e incomensuráveis, como a expressão de uma escolha sem critérios entre essas premissas, um tipo de escolha para o qual não podem ser oferecidas justificações racionais (MACINTYRE, 2007, p. 39).

MacIntyre postula que, na tradição moral aristotélica, seja na versão clássica, como na medieval, juízos morais equivaliam a declarações factuais. Em razão da estrutura de justificação teleológica. Fundamentada, basicamente, no emprego do conceito funcional central de 'homem'. Baseado na concepção do homem como 'organismo orientado para um fim natural'. Noção elementar da biologia metafísica do Filósofo. A modernidade ocidental, porém, caracterizou-se pela rejeição absoluta da tradição moral aristotélica. A partir de então, a estrutura de justificação moral transformou-se radicalmente. Para MacIntyre, a concepção humiana da falácia naturalista, constitui um marco filosófico decisivo nessa transição. Na medida, que Hume sugeriu que juízos factuais não podiam justificar conclusões normativas. Na tradição aristotélica, o homem é concebido, fundamentalmente, como membro de uma comunidade (pólis). Desempenhando papéis sociais determinados. E possuindo certos fins socialmente compartilhados. MacIntyre sugere que uma das características mais significativas da cultura moral contemporânea emotivista, ao contrário, consiste na concepção do 'homem' como um indivíduo desconectado de uma comunidade de interesses. De modo, que os juízos morais passam a expressar unicamente paixões, interesses e fins subjetivos e particulares. Nesse processo de transformação e sucessão das culturas morais ancestrais pela cultural moral da modernidade. Os termos, conceitos e juízos morais mudaram seus significados e funções. Fazendo com que a linguagem moral ingressasse num estágio de desordem progressiva. MacIntyre ressalta que, na tradição moral aristotélica, os juízos morais possuíam o status de declarações factuais. Sendo justificados objetivamente:

A pressuposição desse uso de 'bom' é que cada item do tipo que é apropriado denominar de bom ou mau - incluindo pessoas e ações - possui, como matéria de fato, algum dado propósito ou função específico. Chamar algo bom, portanto, é também fazer uma declaração factual. Chamar uma ação 
particular de justa ou certa é dizer que é o que um homem bom deveria fazer em tal situação; assim esse tipo de declaração é também factual. Nessa tradição declarações morais e valorativas podem ser denominadas de verdadeiras ou falsas precisamente da mesma forma que todas as outras declarações factuais podem ser assim denominadas. Mas uma vez que a noção de propósitos e funções humanas essenciais desapareceu da moralidade, começou a parecer implausível tratar juízos morais como declarações factuais. (MACINTYRE, 2007, p. 59)

MacIntyre sugere que a modernidade, ao rejeitar e descartar, tanto a tradição moral aristotélica (e, consequentemente, a noção de função própria do homem (ergon) e a justificação teleológica), como a tradição moral medieval (e, consequentemente, a noção de Deus como Legislador moral e a justificação teológica). Abandonou os padrões objetivos e impessoais que tradicionalmente garantiam a funcionalidade da moralidade. Não conseguindo substituí-los, satisfatoriamente, nem pela noção de Razão Transcendental (Kantiana), nem pela noção de desejos e paixões (Humiana). MacIntyre sustenta que essa rejeição da justificação teleológica e da justificação teológica, fez com que os juízos morais perdessem seus parâmetros objetivos de validação. Embora, o discurso moral do senso comum contemporâneo, tenha preservado o uso da linguagem e dos conceitos herdados das tradições morais descartadas pela modernidade:

No discurso cotidiano presente persiste o hábito de falar dos juízos morais como sendo verdadeiros e falsos, mas a questão em virtude do que um juízo moral particular é verdadeiro ou falso perdeu qualquer resposta clara. Que isso seja assim é perfeitamente inteligível se a hipótese histórica que esbocei seja verdadeira: que juízos morais são sobreviventes linguísticos das práticas do teísmo clássico que perderam o contexto oferecido por essas práticas. Naquele contexto juízos morais eram hipotéticos e categóricos na forma. (MACINTYRE, 2007, p. 60)

MacIntyre afirma que, na sociedade ocidental, os juízos morais perderam o contexto social e cultural que lhes conferia objetividade. Passando a servir de meios de expressão da cultura emotivista dominante. Desse modo, os enunciados morais passaram a significar, fundamentalmente, expressões subjetivas das intenções e sentimentos particulares dos agentes: 
Juízos morais perderam qualquer status claro e de modo paralelo as sentenças que os expressam perderam qualquer significado inquestionável. Essas sentenças perderam a orientação do contexto no qual eram originalmente familiares perdendo sua forma linguística bem como prática no mundo tornando-se disponíveis como formas de expressão para um eu emotivista. (MACINTYRE, 2007, p.60)

Para MacIntyre, uma característica fundamental da cultura emotivista, consiste em que a linguagem moral adotou uma mascara de objetividade e impessoalidade. Com a finalidade de ocultar os verdadeiros interesses, subjetivos e particulares, que expressa. MacIntyre, através de sua análise histórica, procura desmascarar essas intenções emotivistas. Escondidas sob o véu de uma linguagem moral, disfarçadamente impessoal e objetiva. Mas que é utilizada, deliberadamente, para a realização de interesses inconfessáveis:

A reivindicação de que os maiores protagonistas modernos das causas distintivamente morais do mundo moderno [...] oferecem uma retórica que serve para esconder atrás de mascaras de moralidade o que de fato são preferências arbitrárias de vontades e desejos não é obviamente uma reivindicação original. Porque cada um dos protagonistas contendores da modernidade, enquanto não desejam, por razões óbvias, admitir que a reivindicação é verdadeira no seu próprio caso, estão prontos para fazế-lo contra aqueles com quem contendem. (MACINTYRE, 2007, p. 71)

MacIntyre afirma que uma das características fundamentais do debate moral ocidental, tipicamente emotivista, consiste na tentativa constante dos contendores de desmascarar a mascara de moralidade, utilizada por seus adversários para ocultar interesses arbitrários e particulares:

Quando o emotivismo foi finalmente proclamado como uma tese inteiramente geral sobre a natureza do enunciado moral, nada mais foi feito do que generalizar o que cada partido da revolta cultural no mundo moderno já tinha dito acerca de seus predecessores morais particulares. Desmascarar os motivos não reconhecidos de desejos e vontades arbitrárias que sustentam as máscaras morais da modernidade é por si mesmo uma das atividades mais caracteristicamente modernas. (MACINTYRE, 2007, p.72) 
MacIntyre conclui que a linguagem, os enunciados e, sobretudo, a prática moral contemporânea, incorporaram os pressupostos básicos da emotivismo. De modo, que as pessoas em geral, se comportam, ordinariamente, como se o emotivismo (ou o subjetivismo) tivesse revelado verdades universais e necessárias acerca da natureza da moralidade. MacIntyre afirma que o discurso moral do senso comum ocidental contemporâneo, utiliza, deliberadamente, juízos e asserções formalmente objetivos e imperativos. Herdados das tradições morais antecessoras. Com a finalidade de mascarar a expressão de intenções e interesses particulares e subjetivos. Padrões morais subjetivos e pessoais, típicos das formas-de-vida emotivistas pós-modernas, são, deliberadamente, mascarados ou disfarçados. Através de formas semânticas imperativas e categóricas. Visando, sobretudo, a manipulação da sociedade em geral, e dos agentes particulares, conforme interesses privados. Que refletem padrões morais específicos de uma parcela da sociedade. Especialmente, da oligarquia, da burocracia estatal e das classes dominantes do capitalismo. MacIntyre conclui que a moralidade contemporânea se resume a um teatro de ilusões. Na medida, que uma linguagem moral formalmente categórica, simulando objetividade e impessoalidade. Apela, não sinceramente, para padrões ou princípios que possuem certo prestígio e autoridade moral. Tais como as noções de utilidade, de direitos ou de eficácia política, administrativa ou econômica. Para dissimular interesses subjetivos e particulares. Entretidos pelas parcelas dominantes da sociedade ocidental moderna e pós-moderna. Com o objetivo de manipular outras parcelas. Especialmente, as menos afluentes e influentes no contexto social. MacIntyre sugere que a burocracia estatal cumpre um papel determinante nesse processo. Ao avocar para si uma espécie particular de conhecimento técnico e ou científico acerca da realidade social. Reivindicando autoridade para decidir a respeito das políticas públicas, sociais e econômicas mais relevantes. De modo que, tanto no nível das relações morais 'privadas', como no nível das relações morais 'públicas', a moralidade contemporânea se assemelha a um verdadeiro teatro de ilusões. No qual, a linguagem moral - que preservou a herança conceitual e linguística 
das tradições morais antigas e medievais, e, portanto, seus juízos, termos e enunciados. Os quais, originalmente, remetiam a padrões morais objetivos e impessoais - é utilizada, fundamentalmente, para o engodo e a manipulação de uns sobre outros. Porque o contexto histórico, cultural e social que lhe conferia autoridade moral desapareceu. Tendo sido substituído pelo contexto de uma civilização emotivista. MacIntyre conclui que a linguagem e o discurso moral contemporâneo, sob a máscara de objetividade e impessoalidade, expressa deliberadamente juízos e interesses subjetivos e pessoais dos agentes. Em razão de que os agentes em geral, acreditam fortemente na correção das reivindicações emotivistas. Senão explicitamente, ao menos, implicitamente. MacIntyre delineia esse teatro de ilusões:

Não estaremos apenas justificados em concluir que uma explicação emotivista é tanto verdadeira acerca de, e incorporada em, grande parte de nossa prática e enunciado moral e que muito dessa prática e enunciado é uma negociação de ficções morais (como aquelas da utilidade e dos direitos) [...] Numa extensão perturbadora nossa moralidade será revelada como um teatro de ilusões. (MACINTYRE, 2007, pp. 76-77)

MacIntyre ressalta que um dos aspectos característicos do surgimento da cultura emotivista, consiste na transformação sofrida pelo conceito de fato (ou declarações factuais). Que mudou radicalmente de significado na transição para a modernidade. Sugerindo que, tanto o administrador burocrático, como muitos cientistas físicos - que desempenham papéis sociais fundamentais na modernidade -, reivindicam uma espécie de neutralidade moral acerca de seus conhecimentos e juízos. MacIntyre sugere que a noção de fato foi completamente redefinida pelos filósofos dos séculos XVII e XVIII. Como consequência direta da rejeição da justificação teleológica aristotélica e da justificação teológica medieval. E que esse processo histórico e cultural deu origem. Tanto à célebre tese moderna da dicotomia fato/valor. Concebida, inicialmente, por Hume, ao propor uma distinção ontológica radical entre juízos de fato e relações de ideias (equivalentes a juízos de valor). Como propiciou o surgimento do sujeito moral autônomo. Duas concepções ele- 
mentares da cultura e da moralidade da sociedade ocidental moderna, tipicamente emotivista:

Essa emergência envolve uma rejeição a todas as visões de mundo aristotélicas ou quase-aristotélicas nas quais a perspectiva teleológica fornecia um contexto no qual reivindicações valorativas funcionavam como uma espécie particular de reivindicação factual. E com essa rejeição ambos os conceitos de fato e valor adquiriram um novo caráter. (MacIntye, 2007, p. 77)

MacIntyre sugere que o surgimento da noção de sujeito moral autônomo - origem do self emotivista contemporâneo na filosofia moderna. É resultado do mesmo processo histórico de transformação da tradição moral ocidental, no qual o agente moral deixou de ser concebido basicamente como um animal social (conforme a famosa concepção de Aristóteles). Intimamente vinculado a sua comunidade política e moral. Na visão aristotélica. Desenvolvida especialmente no Tratado da Felicidade, livro I, da Ethica Nicomachea (ARISTOTLE, trad. Irwin, 1999, pp. 1-16). O homem somente pode desenvolver plenamente suas potencialidades, e, sobretudo, atingir a eudaimonia, como membro da pólis. Entendida como comunidade social, política e moral. Desse modo, a pólis constituía a condição ontológica fundamental do conceito de homem. O homem aristotélico sente-se profundamente vinculado e comprometido com a sua comunidade moral. Compartilhando interesses, sentimentos e finalidades com seus pares. Nesse contexto. A linguagem e os juízos morais expressam padrões culturais objetivos e impessoais. Amplamente compartilhados pelos cidadãos da pólis. Na justificação teológica, típica da sociedade medieval, por sua vez, a noção de Deus oferecia, igualmente, um padrão objetivo e impessoal, amplamente compartilhado. De modo que os juízos morais verdadeiros deviam se adequar aos fins validados teologicamente, conforme a lei e a vontade do Legislador Universal. Reveladas, interpretadas e, sobretudo, garantidas, pela autoridade secular da Igreja. Essas características da sociedade medieval garantiam a validade dos padrões morais objetivos e impessoais, propiciando um amplo consenso moral. MacIntyre reivindica que a sociedade moderna perdeu esses contextos so- 
ciais, históricos e culturais, amplamente compartilhados. Tornando-se numa sociedade fragmentada e dividida conforme interesses e finalidades particulares, pessoais e subjetivas. Sugerindo que o desacordo moral contemporâneo, aparentemente, ao menos, infindável, é o resultado do surgimento dessas novas formas e relações sociais e de poder. Que privilegiam interesses privados em detrimento de interesses socialmente compartilhados. Dessa maneira, o homem deixou de ser considerado, fundamentalmente, um membro da pólis ou uma criatura de Deus. Para assumir uma autonomia moral absoluta. De maneira que os juízos morais devem expressar basicamente interesses pessoais e subjetivos. Como consequência filosófica dessa rejeição das tradições morais teleológicas e teológicas. Hume, em A Treatise of Human Nature, pode conceber a dicotomia fato/valor e a falácia naturalista (HUME, 1978, pp. 469-470). Postulando que, a partir de premissas ou juízos puramente descritivos ou naturais (ser/is), não seria logicamente possível, inferir ou deduzir, juízos ou conclusões puramente normativas ou valorativas (dever ser/ought). MacIntyre argumenta que essa falácia naturalista não constitui uma verdade lógica ou ontológica, universal e necessária. Mas apenas um postulado cultural, típico da sociedade e do pensamento caracteristicamente moderno. MacIntyre traça um panorama dessa transformação do conceito de fato e do surgimento da dicotomia fato/valor:

Portanto não é uma verdade eterna que conclusões morais ou de outra forma valorativas não possam estar implicadas por premissas factuais; mas é verdade que o significado atribuído às expressões morais e de fato às outras expressões avaliativas chaves mudou entre o final do século dezessete e o século dezoito, de modo, que o que era então comumente admitido como premissas factuais não poderia estar implicado pelo que então era comumente tido como conclusões morais ou valorativas. A promulgação histórica dessa aparente divisão entre fato e valor não foi, entretanto, meramente uma questão da nova maneira pela qual valor e moralidade vieram a ser concebidas; foi também reforçada por uma concepção de fato mudada e em mudança [...] (MACINTYRE, 2007, pp. 77-78).

A posição de MacIntyre é bastante semelhante à tese defendida por Putnam, em The Collapse of Fact/Value Dichotomy. Nessa obra, Putnam sustenta que o conceito de "fato" sofreu 
significativa transformação, entre o século XVII e nossos dias, como resultado do advento de uma nova visão científica do mundo. Especialmente, em razão do enorme sucesso tecnológico obtido pela introdução das teorias da relatividade e da mecânica quântica. Dessa forma, a noção de "fato" deixou de ser vinculada diretamente a noção de "impressão sensorial", como propunha o empirismo clássico. Porque novos "objetos" científicos, tais como fótons, nêutrons, elétrons, etc., não podiam ser imediatamente percebidos pelos órgãos sensoriais. E uma descrição científica factual do mundo não poderia mais prescindir desses "objetos". Dessa forma, a noção de "fato" foi desvinculada da noção de "impressão sensorial". De modo, que, a partir de então, a ideia de uma dicotomia ontológica entre "fatos" e "valores" entrou em colapso no pensamento pós-moderno.

\section{Discussão}

A investigação desenvolvida analisou os aspectos filosóficos mais relevantes de dois possíveis mundos morais ocidentais contemporâneos, absolutamente contraditórios entre si: o mundo moral concebido por Mackie. No qual, os valores morais são subjetivos, não possuindo objetividade ontológica; e o mundo moral concebido por MacIntyre. No qual, valores morais podem ser objetivos, possuindo objetividade ontológica sócio-cultural. Desenvolvendo uma contraposição direta entre o ceticismo moral de Mackie e o contextualismo moral de MacIntyre. Concluindo que as teorias éticas de Mackie e MacIntyre são diametralmente opostas entre si, ontologicamente e linguisticamente. Oferecendo visões divergentes a respeito, tanto do status ontológico ou metafísico dos valores morais, quanto do uso da linguagem moral na sociedade ocidental contemporânea. O ceticismo moral de Mackie sugere que a crença disseminada na cultura ocidental a respeito da objetividade dos valores morais. Incorporada, fortemente, tanto por parte do senso comum, como pela parcela amplamente majoritária da filosofia moral. Constitui um grave equívoco ontológico. Do ponto-de-vista linguístico. Mackie afirma que o uso cotidiano da linguagem moral, na sociedade ocidental contemporânea. É 
baseado, fundamentalmente, nessa crença falsa acerca da $o b$ jetividade dos valores, juízos e enunciados morais. Sugerindo que o uso da linguagem moral ocidental tradicional, em nossa cultura contemporânea. É determinado, basicamente, pela crença sincera dos agentes na natureza objetiva, imperativa e categórica dos valores morais, expressos em seus juízos e asserções. Sendo que essa crença sincera na objetividade dos valores morais. Amplamente incorporada na forma como a linguagem moral é utilizada e compreendida. Tanto pelos agentes em geral, como pela maioria dos filósofos. Constituindo, assim, um traço cultural essencial da sociedade ocidental. Implica, justamente, no que Mackie denuncia como um grave 'erro' ontológico e linguístico. Esse 'erro'. Entranhado na cultura ocidental. Se expressa, tanto nos juízos e práticas da moralidade típica da vida cotidiana. Através dos juízos morais de primeira ordem, que envolvem pretensões implícitas de imperatividade. Como na análise ética filosófica. Através dos juízos morais de segunda ordem, que reivindicam teoricamente a objetividade ontológica dos valores morais. Mackie sugere, enfim, que os agentes morais acreditam sinceramente na objetividade dos valores morais. E que essa crença se expressa através do uso da linguagem moral tradicional. O ponto é que, para Mackie, essa crença é falsa. Porque, na verdade, valores morais expressam escolhas, interesses e finalidades subjetivas desses agentes. Putnam sustenta que a teoria do 'erro' de Mackie possui natureza eminentemente linguística. Sendo baseada numa análise acerca do uso da linguagem moral. Para Putnam, a teoria do 'erro' postula, basicamente, que o uso moral tradicional do termo 'bom', se refere a uma suposta propriedade ontológica possuída por ações, finalidades, sentimentos, vontades, etc. De modo, que o reconhecimento dessa propriedade ontológica seria capaz de motivar moralmente, de maneira necessária, todo e qualquer agente racional. Putnam sustenta que, para Mackie, essa propriedade ontológica simplesmente não existe. Razão pela qual, cada vez que o agente emprega o termo 'bom' comete um erro metafísico. Putnam sugere que Mackie teria sido influenciado pelo emotivismo. Porque a teoria do 'erro' seria baseada, funda- 
mentalmente, numa descrição do uso da palavra 'bom', muito semelhante aquela proposta pelos emotivistas.

Putnam interpreta a teoria do "erro", nesses termos:

Ao contrário, ele adota sua famosa "teoria do erro", conforme a qual, "bom" significa uma propriedade cujo conhecimento de que alguma coisa a possui, supostamente, motiva necessariamente a pessoa que possui esse conhecimento a desejá-la e preferi-la. Como não pode existir tal propriedade (conforme Mackie), toda vez que dizemos que algo é "bom" estamos cometendo um erro (um erro metafísico, de fato: atribuindo a algo uma propriedade metafisicamente absurda). (PUTNAM, 2002, p. 43)

Apesar de reconhecer que Mackie não concorda com a noção emotivista de que juízos morais necessariamente expressam desejos ou preferências dos agentes. Putnam aponta a razão pela qual atribui uma influência decisiva do emotivismo na concepção da "teoria do erro":

A razão pela qual, entretanto, atribuo a Mackie uma influência emotivista consiste em que seu argumento a respeito do absurdo metafísico da bondade se baseia em uma descrição de como a palavra "bom" é usada, e essa descrição foi (como Hare) fortemente influenciada pelo emotivismo. (PUTNAM, 2002, p. 43)

MacIntyre sugere, ao contrário, que a cultura moral ocidental contemporânea incorporou, em larga medida, as reivindicações do emotivismo. Reivindicando que os agentes morais ocidentais pós-modernos, em geral, acreditam, sinceramente, na natureza, necessariamente, subjetiva dos valores morais. MacIntyre sustenta que um traço fundamental da cultura moral contemporânea. Consiste na crença de que valores morais, necessariamente, expressam as escolhas, interesses e sentimentos de um agente moral autônomo e livre. Um agente que pode deliberar pessoalmente acerca do melhor conjunto de valores morais para si mesmo. Na modernidade e pós-modernidade. Os agentes empregam a linguagem moral tradicional. Que constitui uma herança cultural das civilizações passadas. Caracterizada pelo apelo a padrões morais que foram concebidos, originalmente, como objetivos e impessoais. No contexto das estruturas 
sociais e tradições morais antigas e medievais. Para expressar, basicamente, interesses e desejos subjetivos. Para MacIntyre, a linguagem moral tradicional, formalmente imperativa, é utilizada deliberadamente, pelos agentes contemporâneos, para encobrir suas reais intenções particulares e subjetivas. Com a finalidade principal de manipular outros agentes conforme seus interesses pessoais. MacIntyre afirma que o senso comum da sociedade ocidental contemporânea é caracterizado pela crença disseminada na subjetividade dos valores morais. E que essa crença foi incorporada no uso da linguagem moral cotidiana. Dessa maneira, os agentes em geral utilizam a linguagem moral tradicional, formalmente categórica. Caracterizada por conceitos e termos morais concebidos originalmente - no contexto das tradições morais antigas e medievais - como objetivos e imperativos. Para mascarar suas reais intenções e interesses pessoais particulares. Visando manipular as relações interpessoais. 'Outra distinção fundamental entre as posições de Mackie e MacIntyre diz respeito ao tipo de ontologia adotada. Mackie fundamenta seu ceticismo moral em uma ontologia geral - e não apenas numa ontologia moral, porque sua teoria se aplica tanto a valores morais como a valores estéticos, por exemplo - claramente fisicalista ou materialista. Baseada, em larga medida, nos pressupostos elementares da tese da dicotomia fato/valor. Putnam analisa como essa ontologia fisicalista determina fundamentalmente o ceticismo moral e a teoria do "erro" de Mackie:

Mackie [...] foi atraído por uma concepção fisicalista dos fatos, tentando explorar uma propriedade que ele reivindica que os juízos éticos possuem: que alguém não pode realizar um juízo ético e considerá-lo como um juízo ético sincero, a menos que expresse um desejo ou preferência real. Desde que descrições de fato não podem, conforme Mackie, ser expressões de desejos e preferências, segue-se que juízos éticos não são descrições de fato [...] (PUTNAM, 2002, p. 42)

Putnam sustenta que, essa propriedade atribuída aos juízos morais por Mackie, possui origem filosófica no emotivismo, concebido pelos Positivistas Lógicos. Na medida, que a reivindicação fundamental do emotivismo sugere que a única "função" dos juízos morais, necessariamente (por sua natureza ontológica), consiste em expressar desejos e preferências dos agentes. 
Como referimos anteriormente. Putnam sugere que Mackie, porém, não compartilha dessa tese emotivista. O ponto é que, para Mackie, juízos morais podem ser defendidos racionalmente, no contexto de uma convenção cultural e ou moral. Desse modo, juízos morais podem também expressar crenças racionais e tradições culturais contingentes, amplamente compartilhadas por uma comunidade humana. Podendo ser justificados intersubjetivamente. Mackie, porém, distingue intersubjetividade de objetividade ontológica. O ponto é que a tese da dicotomia fato/valor, concebida inicialmente pelo emotivismo, reivindica existir uma dicotomia ontológica entre juízos de fato e juízos de valor. Postulando que juízos factuais ou empíricos são ontologicamente objetivos. Enquanto, em contraposição, juízos valorativos ou normativos são ontologicamente subjetivos. Mackie parece crer que essa dicotomia constitui uma verdade ontológica, universal e necessária. Essa ontologia fisicalista é baseada numa concepção de fato vinculada basicamente a noção de impressão sensorial. Considerando como 'fatos objetivos' unicamente aqueles fenômenos que são, mediata ou imediatamente, perceptíveis pelos órgãos sensoriais. Reivindico que é justamente essa ontologia fisicalista. E unicamente ela. Que confere inteligibilidade ao problema filosófico proposto por Mackie, ao questionar se valores morais fariam ou não fariam parte da estrutura do mundo. Hare, por exemplo, considera esse tipo de questionamento absolutamente ininteligível (HARE, 1972, p. 47). Mackie sugere que valores morais não podem ser considerados objetivos porque não possuem as mesmas propriedades ontológicas dos objetos ou entidades espaço-temporais que constituem os fatos empíricos. Sustentando que valores morais são subjetivos. Possuindo existência, unicamente, no universo mental, racional, sentimental ou volitivo privado dos agentes que os enunciam. Expressando suas escolhas, finalidades e interesses particulares. Mackie adota uma ontologia transcendental típica do realismo metafísico. Ao reivindicar que juízos morais não fazem parte da estrutura do mundo. Partindo da noção epistemológica ortodoxa de que existe apenas um mundo real, absoluto e objetivo, independentemente das crenças, teorias, culturas e conceitos humanos. Um mundo que contém objetos reais limita- 
dos. Isso se torna evidente na distinção, proposta por Mackie, entre objetividade e intersubjetividade. A noção de objetividade de Mackie não admite valores morais contingentes. Para Mackie, valores morais objetivos deveriam possuir natureza metafísica transcendental, como integrantes da composição material eterna da realidade empírica. Mackie adota, claramente, uma espécie de realismo metafísico. Caracterizado, basicamente, pela crença na existência de uma realidade ou um mundo 'em si' (conforme o jargão kantiano). Absolutamente independente da percepção sensorial, das teorias epistemológicas, dos conceitos ontológicos e das linguagens (ou jogos-de-linguagem) humanos. Mackie postula um mundo transcendental, que possui existência absoluta e eterna. Constituído por um número limitado e fixo de objetos reais. Um mundo que não possui qualquer relação necessária com a realidade contingente, histórica, social e cultural dos seres humanos e suas comunidades. $\mathrm{O}$ ceticismo moral de Mackie exige, portanto, compromissos ontológicos (conforme a expressão célebre de Quine) metafísicos acerca da existência de uma realidade ou mundo 'em si'. A noção de objetividade como correspondente a descrição factual do mundo, pressupõe a existência de fatos brutos. Absolutamente independentes das teorias ontológicas e epistemológicas que justificam os enunciados factuais e as teorias empíricas. MacIntyre, por sua vez, fundamenta o contextualismo moral. E, especialmente, sua tese acerca do desacordo moral contemporâneo, como expressão de uma cultura emotivista. Tanto em uma ontologia geral, baseada na rejeição absoluta da dicotomia fato/valor. Como em uma ontologia social e cultural, baseada na afirmação da objetividade das tradições culturais e convenções sociais. Para MacIntyre, as tradições e práticas morais, entretidas por comunidades humanas historicamente localizadas, possuem objetividade ontológica. MacIntyre sustenta que é o contexto (holístico) social, cultural e histórico, como um todo, que confere objetividade aos valores morais. Reivindicando que a objetividade dos valores morais é garantida por sua intersubjetividade e impessoalidade. E não pela eventual possibilidade ou não de sua percepção sensorial. Valores morais estão ontologicamente vinculados às práticas sociais e tradições culturais 
historicamente localizadas. Somente podendo ser considerados racionais, objetivos e inteligíveis, no 'interior' (justificação internalista ou Neurathiana) de um conjunto de crenças particulares, compartilhadas amplamente por uma comunidade humana. Nesse sentido, valores morais possuem natureza contingente. A tese de MacIntyre acerca do desacordo moral contemporâneo e da supremacia da cultura emotivista na sociedade ocidental contemporânea. Afirma que a crença disseminada na verdade do subjetivismo moral. Que determina o uso da linguagem e dos juízos morais tradicionais (formalmente objetivos e imperativos) para mascarar a expressão de interesses subjetivos. Constitui, unicamente, um traço característico da sociedade e da cultura ocidental moderna e pós-moderna. MacIntyre ressalta, porém, que esse tipo de subjetivismo emotivista constitui apenas uma característica contingente da moralidade ocidental em certo estágio de seu processo histórico. Não constituindo uma verdade ética universal e necessária. MacIntyre, ao contrário, acredita que juízos e valores morais podem ser plenamente objetivos. Como de fato, já o foram, nas sociedades antigas e medievais. MacIntyre postula que o emotivismo pode constituir uma posição ética consistente. Apenas quando é entendido como uma tese linguística, histórica e sociológica. Que procura descrever o uso da linguagem moral por determinadas comunidades humanas, em períodos específicos de sua evolução cultural. E não como uma tese ontológica, universal e necessária, acerca do significado dos enunciados morais. MacIntyre sugere que a linguagem moral pode ser usada para expressar interesses pessoais e subjetivos. Como, de fato, é usada na cultura emotivista da sociedade ocidental contemporânea. Mas rejeita a hipótese de que toda e qualquer linguagem. Empregada, em qualquer tempo e sociedade, para expressar valores morais. Se refira, necessariamente, por sua natureza ontológica, a enunciação de sentimentos, paixões e interesses puramente subjetivos. Para MacIntyre, quando a linguagem moral encontra-se num estado de ordem. Estando adaptada a seu contexto histórico sócio-cultural. Os valores e os juízos morais que ela expressa oferecem padrões objetivos e impessoais de justificação. Possuindo, portanto, objetividade ontológica e epistemológica. Sendo capazes de cumprir plenamente suas funções de justifi- 
cação da moralidade. Garantindo, dessa forma, um amplo consenso acerca dos problemas morais mais relevantes. Nesse estágio plenamente funcional da moralidade. Os contendores do debate moral apelam para valores ou padrões, reconhecidos como racionais e justificáveis, por todas as partes envolvidas na disputa. De modo, que esse acordo intersubjetivo acerca da $o b$ jetividade dos valores morais, permite que uma conclusão amplamente aceita possa ser alcançada. Outro contraste entre os mundos morais concebidos por Mackie e MacIntyre, diz respeito à natureza da análise filosófica proposta. MacIntyre propõe uma análise histórica e sociológica. Baseada na pressuposição de que valores morais constituem construções culturais contingentes. Mackie propõe uma analise ontológica acerca do status dos valores morais. Procurando estabelecer se eles fazem ou não parte da estrutura do mundo. Afirmando que análises linguísticas ou conceituas não podem revelar o 'erro' fundamental, cometido pelo senso comum e pela maioria dos filósofos ocidentais, ao atribuírem objetividade aos valores morais. Porque essa crença foi incorporada fortemente na linguagem moral ocidental. De modo, que uma análise que se concentre unicamente no significado dos juízos, termos, conceitos e enunciados morais. Comumente utilizados na vida cotidiana em nossa sociedade. Concluirá necessariamente que eles expressam pretensões imperativas ou categóricas por parte dos agentes. Na medida, que a crença na objetividade dos valores morais constitui, conforme Mackie, uma característica fundamental da cultura ocidental. As pessoas em geral utilizam a linguagem moral tradicional realmente para expressar sua crença sincera na objetividade dos valores morais. Sendo, justamente, por essa razão, que Mackie propõe uma teoria do erro. Reivindicando que essa crença é falsa, constituindo um grave equívoco ontológico. Sugerindo que o reconhecimento da natureza subjetiva dos valores morais - ou seja, que eles expressam escolhas, finalidades, interesses e inclinações pessoais dos agentes - permite uma compreensão mais adequada da moralidade. Sem implicar em relativismo ou ameaçar as funções sociais das práticas morais que garantem uma convivência relativamente harmoniosa entre os membros de uma comunidade. 


\section{Conclusão}

Concluo que os mundos (morais) possíveis de Mackie e MacIntyre são ontologicamente e linguisticamente absolutamente contraditórios. Podemos habitar o mundo sem valores morais objetivos de Mackie, ou o mundo com valores morais objetivos de MacIntyre. Mas não podemos habitar esses dois mundos possíveis ao mesmo tempo. Porque eles são irreconciliáveis filosoficamente. De um ponto de vista linguístico. O mundo (moral) que habitamos, na sociedade ocidental contemporânea, pode ser o mundo de Mackie. No qual, o uso da linguagem moral pressupõe falsamente a objetividade dos valores morais. Ou pode ser o mundo de MacIntyre. No qual, o uso da linguagem moral é baseado na crença (falsa) na subjetividade dos valores morais. De um ponto de vista ontológico. Mackie adota uma ontologia fisicalista. Reivindicando que apenas objetos espaço-temporais, imediatamente perceptíveis sensorialmente, possuem o atributo da objetividade ontológica. Mackie postula que uma justificação moral intersubjetiva não confere objetividade aos valores morais. Concluindo, portanto, que valores morais são ontologicamente subjetivos. Expressando crenças (racionais ou não), desejos e ou preferências dos agentes. De um ponto de vista lógico. Essa conclusão de Mackie implica em que, toda e qualquer justificação da moralidade, é necessariamente baseada em uma, ou mais, premissas subjetivas. De modo, que juízos morais não constituem imperativos lógicos da Razão. Para Mackie, a justificação dos valores morais é, portanto, relativa. Desse mesmo ponto de vista ontológico. MacIntyre adota uma ontologia social ou cultural. Reivindicando que crenças, tradições, valores possuem o atributo da objetividade ontológica. MacIntyre sustenta, portanto, que convenções sociais e culturais constituem realidades ontologicamente objetivas. Dessa forma, valores morais podem ser justificados racionalmente no "interior" de uma tradição moral. MacIntyre acredita que, tanto a noção de racionalidade como de moralidade, fazem parte um sistema holístico de crenças mais amplo. De modo, que a justificação racional da moralidade somente pode ser ontologicamente objetiva no "interior" de um sistema holístico de crenças. Dessa forma, MacIntyre propõe uma justificação moral "internalista". Baseado 
na pressuposição de que valores morais são construções culturais contingentes. MacIntyre conclui que valores morais podem ser ontologicamente objetivos e racionalmente justificados, apenas contingentemente. No estágio histórico de uma moralidade ordenada e funcional. Para MacIntyre, ao contrário de Mackie, portanto, objetividade ontológica equivale a intersubjetividade. Por todas essas razões. Os mundos (morais) possíveis de Mackie e MacIntyre podem ser ambos falsos, mas não podem ser ambos simultaneamente verdadeiros.

\section{Referências:}

HARE, R. M. don, The Macmillan Press Ltda, 1972.

Applications of Moral Philosophy, Lon-

HUME, David, Oxford University Press, 1978.

A Treatise of Human Nature, Oxford,

IRWIN, Terence

Aristotle Nicomachean Ethics, Indianapolis/Cambridge, Hackett Publishing Company, Inc., 1999.

LOCKE, John An Essay Concerning Human Understanding, Oxford, Clarendon Press, 1975.

LOCKE, John An Essay Concerning Human Understanding, Pennsylvania State University, 1999.

MCDOWELL, John Harvard University Press, 2002.

Mind, Value and Reality, Cambridge,

MACINTYRE, Alasdair Whose Justice? Which Rationality?, Notre Dame, University of Notre Dame Press, 1998.

MACINTYRE, Alasdair After Virtue: A Study on Moral Theory, $3^{\mathrm{a}}$ edição, Notre Dame, University of Notre Dame Press, 2007.

MACKIE, J.L. Ethics: Inventing Right and Wrong, $2^{\mathrm{a}}$ edição, London, Penguin Books, 1990.

PUTNAM, Hillary The Collapse of the Fact/Value Dicothomy and Other Essays, Cambridge, Harvard University Press, 2002. 
